\title{
KNOWLEDGE MANAGEMENT: APPLICATION IN VOCATIONAL TRAINING ORGANIZATIONS - CASE STUDY
}

\author{
Eduardo Marques da Fonseca ${ }^{1}$, Luís Farinha ${ }^{2}$ \\ ${ }^{1}$ Polythecnic Institute of Castelo Branco, Higher School of Management, \\ Largo do Municipio, 6060-163 Idanha-a-Nova \\ ${ }^{2}$ PolythecnicInstituteof Castelo Branco, CIPEC and NECE research center in Business Sciences, \\ Largo do Municipio, 6060-163 Idanha-a-Nova \\ E-mails: eddyfonseca@gmail.com, Luis.farinha@ipcb.pt
}

\begin{abstract}
Knowledge Management has proven to be a key element in how organizations can innovate and, therefore, enhance the skills of their employees, especially through the acquisition, creation, storage and dissemination of knowledge, acting to facilitate the integration of human resources while contributing to the creation of competitive advantages. Among these organizations, the entities that have their own knowledge as a product assume a key role in society, as they are responsible for knowledge transfer and skills development with a view in a better performance of citizens.

The objectives of this investigation are the analysis of the knowledge Management process, and the understanding of the influence of this process on the success of the vocational education practiced and, consequently, on the valorisation and reinforcement of the organization's competitiveness. To achieve these objectives, a multiple case study was developed and structured by a quantitative and qualitative analysis using interviews, questionnaire, and document analysis in two vocational education organizations in the Automotive Technology area, one in Portugal and other in Spain.

The result pointed out that the knowledge Management practices are known to the management and employees of the entities and, although in a not well-structured way, there are activities aimed to improve the knowledge of human resources and there is a concern to reflect this improvement on success of the professional training developed.
\end{abstract}

Keywords: Knowledge Management, Vocational Training, Innovation, Skills.

\section{Introduction}

For some years now, we have been witnessing the evolution of industrial-type production to knowledge-based production, which has contributed to what we now call globalization and the knowledge society, which is - in recent times - mentioned in studies that address the changes in the world economy, because it is believed that this is where the "secret" of business success lies, as stated by Martins (2018, p. 78). "The only source of advantage sustainable competition is knowledge, and its acquisition and creation are continually stimulated by the environment" [9] or, as Nonaka (2007, p.162) points out, "In an economy where uncertainty is the only certainty, the right source of lasting competitive advantage is knowledge"[10].

Thus, knowledge is a recognized tool that is increasingly used because it gives advantage to those who have it, it is natural that human resources feel valued for having it, as well as companies for using it to create solidity.

However, in order to acquire and / or develop this knowledge, society, especially the productive area, has seen vocational training as a vital instrument, including the possibility of contributing to the social integration of citizens through the creation and strengthening their competencies. As stated by Rodrigues (2016, p.3) "It is impossible to dissociate the practices of company formation from their growth strategies, especially in large companies, multinationals, involved in globalization and challenged by competitiveness requirements of supranational scope" [14].

With these changes, it is especially important to understand the impact of Knowledge Management (KM) on the vocational training process, especially in organizations where knowledge and the creation of skills - through vocational training - is its main activity. Given the difficulty in finding studies on KMin vocational training contexts, especially in the public area, it is understood that this reality is still poorly studied, or as stated by Batista (2004, p.71) "Knowledge Management in public organizations is a topic that has still deserved little attention from analysts" [2].

In this context, exploring this theme will be the best way to add information about a problem that 
may give the feeling of not existing because, well or badly, knowledge is being transmitted and skills are emerging, and the market will be responsible eto select the better prepared ones. By way of example in order to better understand what we are looking for - the following question may be asked: When a training technician is lost without his knowledge being left in the organization (because even those he taught have gone too), is the organization's knowledge being managed well? or this one: The non-healing organization of knowledge creation and knowledge dissemination, is preparing itself and, concomitantly, prepares the ones that forms for market challenges?

This work intends to contribute, in some way, to the enrichment of the knowledge related to the vocational training, and to the KM, as well as to the way that the two areas can interact and influence each other, allowing the availability of a theoretical basis that will serve for the implementation of future studies. The investigation of these phenomena will also contribute to the identification of the state of development of $\mathrm{KM}$, as well as the presentation of possible solutions that add value to this area of the organizations analyzed.

To this end, the research strategy is based on the methodology of study of multiple cases in two vocational education institutions, because it is understood that is the one that best fits the type of study and the objectives to be achieved. To do this the theoretical analysis is a fundamental pillar for the deepening of the knowledge about the phenomenon under analysis and, consequently, for the solidification of the several stages of the work.

\section{Theoretical Framework}

The knowledge society has, intrinsically, the indication that it is a knowledge based and dependent society as a form of growth and guarantee of social welfare. Given the explanation in the United Nations (UN) report (2005) its essence lies in the ability to develop knowledge or "create new meaning" by processing existing information to create more value and usefulness and, in this case, all societies could be considered knowledge societies. However, the great difference of the current society, still according to the same point of view, UN (2005) resides in the quantity and speed with which knowledge arises, being certain that the arrival and expansion of new technologies, as well as the increase of spaces of knowledge creation and development, has contributed to generalization [22], as Stewart (1999, p.44) states: "As with the Industrial Revolution, the Information Revolution also affects everything"[19].

In the knowledge society, according to the UN $(2005$, p.25), it is verified that "people with high development are the most important resource", highlighting the encouragement of creativity in order to enrich tacit knowledge and the consequent human development. Thus, two important assets in the knowledge society are people and information and both, with the support of technology, can develop without geographical limits and with great ease. In this sense is the vision of Lopes (2013, p.23) "The information society, based on a knowledge-based economy, supported by digital means and continuous processes of innovation, constantly calls for creativity, dynamism, the development of new organizational processes and Global Information Management"[5], or in Stewart's opinion (1999, p.49) "As with sand in a beach house, information penetrates everywhere".

In this way, another significant aspect for the development of this type of societies is the way in which the institutions that can contribute to the creation and development of knowledge are organized, especially those that rely on the so-called "knowledge workers", for UN ( 2005, p. 36), "It is useful to see" new meaning factories" not only in $\mathrm{R} \& \mathrm{D}$ labs, but also in service companies and in communities with a high concentration of such companies or" knowledge workers" which ultimately allows us to arrive at a society in which it itself becomes a "factory of knowledge".

However, according to Straus teal. (2012, p.20) "In the Knowledge Society, education and social relations take on great importance because knowledge creation environments require much more than technology, they require people in permanent sharing of ideas"[18]. It is perhaps this valence that could lead to what the UN (2005, p.47) calls the "Intelligent Knowledge Society", and which involves the ability to modify institutions to make them the driving force for change, "Institutional changes open broad avenues for the unlimited development of people and information and rebuild social organizations for the mass production and use of knowledge", realizing that in addition to technology people and a favourable environment are needed, where education and training are vital for these societies to be successful, as stated by Lopes (2013, p.23) "We have abandoned the age of scarcity to gradually enter the age of abundance of the most intangible resource to be managed - Knowledge".

Although knowledge is more than information, since it involves the understanding obtained through experience and learning, there is an interaction between the two, as stated by Martins (2018, p.17). "The development of relevant information requires the application of knowledge". Using the United Nations Development Program's knowledge management point of view, we can go even further, UNDP (2007, p.2), as it distinguishes information or its management as "being focused on data collection, structuring and processing" and knowledge or its management as "information derived, but also implies an analysis of information and data and an understanding of that analysis. It also allows the 
application of this understanding in future practice" [23].

In this follow-up, we have the data as a result of the various processes and interactions and, as Lopez (2014) argues, being properly treated, using statistical, mathematical or simple organization, it is possible to obtain information that, in organizations, is of utmost importance to your organizational management system. In terms of utility [6], Straus et al. (2012, p.11) state that "Information and knowledge are fundamental in all stages of the innovation process: in the generation and selection of ideas, (...) and especially in organizational learning. This last step greatly benefits from understanding the differences between data, information and knowledge".

At the corporate level, in Nonaka's (2007) view, companies are constantly confronted with changes in the market, technologies and products, so the ability to resist is dependent on their ability to create new knowledge and to know how to spread it. This is because of its organizational structure, and this way of being defines the "knowledge creator" company, whose "sustenance" is uninterrupted innovation.

This ability has individuals as a fundamental element for the production of knowledge, for decades that Sveiby (1998, p. 9) reported that "People are the only true agents in the company. All assets and structures - whether tangible or intangible - are the result of human actions. Everyone depends on people, ultimately, to continue to exist" [20], or as Magalhães (2005, p.87) points out "The theory of the creation of organizational knowledge is based on the relationship between people at all levels - individual, group, organizational and inter-organizational relationships and, as is well known, relationships depend on the existence of facilitating contexts" [7].

Regarding the knowledge that people have, it is interesting to understand the concept of tacit and explicit knowledge. At the level of tacit knowledge, according to Nonaka's understanding (2007, p.165) "Tacit knowledge consists in part of technical skills informal, hard-to-trace skills included in the term 'know-how'. (...) it is often unable to articulate the scientific or technical principles behind what he knows" and here is the reference to technicians, often with many years of experience. Interesting, too, is the point of view of Wan, Zeng \& Zhu (2013, p.96) in stating that people "show self-satisfaction by possessing knowledge that others lack, even keep it secret, and feel superiority. for owning a scarce resource"[25] making tacit knowledge something that distinguishes them and should be valued. It can be summarized in this way: tacit knowledge, what is stored in the minds of employees, and that for Takeushi \& Nonaka (2008), tacit knowledge is constituted by cognitive and technical elements, and the cognitive ones are the result of perceptions and beliefs allowing the creation of a worldview in which individuals operate, including the working world [21], while the technician, Takeushi \& Nonaka (2008, p.58) "includes know-how, crafts and concrete skills".

With regard to explicit knowledge, according to Martins (2018, p.20) it is capable of being recorded, coded and transmitted through "symbols (writing, drawing) or embodied in a tangible form (machinery, tools), and means' know what". In contrast to tacit knowledge (personal and subjective), explicit knowledge is easily transferable, whether through data, symbols, specifications or manuals.

Although distinct, these two strands of knowledge complement each other and, according to Nonaka (2007), are the origin of the process of knowledge creation in any organization, suggesting, for this, the existence of four basic patterns:

- Tacit/Tacit, which happens when an individual shares knowledge with another, but the organization cannot easily take advantage of it;

- Explicit/Explicit, arises when someone collects information from the entire organization and uses it for a financial report, for example. In this way, new knowledge is generated from what already existed but dispersed;

- Tacit/Explicit, can arise when an innovation is shared and can be used by others as long as it is easily understood;

- Explicit/Tacit, exists from the moment knowledge is assimilated, because it belongs to the individual, which means that it starts to use it to broaden its tacit knowledge.

Beyond what is described, the creation of knowledge, according to Martins (2018) is "a dynamic human process that stems from "interactions" between individuals and between them and their environment", and for the organization to make it profitable this should be done continuously, and in this context, the process of knowledge creation in organizations, made available by Takeushi \& Nonaka (2008), is made up of three elements: The $\mathrm{Ba}, \mathrm{SECI}$, and the Knowledge Assets.

In the case of ba, it is understood as the - physical or virtual - place in which information is transformed into knowledge by the interaction dynamics of those involved. Martins (2018, p.39) sums ba as "a shared context that enables the development of its participants through selftranscendence resulting from a commitment to create knowledge through their interaction".

Regarding the SECI (Socialization, Externalization, Combination and Internalization) element, according to Martins (2018, p.43), they allow the creation of a different "content of knowledge" whereas "Socialization produces 'understood knowledge' (...), the Externalization produces' conceptual knowledge'(...) the Combination gives rise to 'organic knowledge'”, such as new components, or new technology, and 
"Internalization generates' operational knowledge'”, which refers to use of new products, production processes, or project management, for example.

With regard to the company's knowledge Assets, these are defined by Martins (2018, p.46) as "specific resources - inputs and outputs - which constitute its knowledge base", and has to do with the company culture; the procedures; the symbols; the concept of the product; the transmission of experience among employees; the skills of know-how; customer/supplier data and patents, for example.

In these processes of knowledge creation and transference, the importance of the various levels of the organizational structure is emphasized. According to Martins (2018, p.25), "the first-line employees" as those who deal daily with the market "Although they have plenty of practical information" they have great difficulty converting the information into valid knowledge for the organization. Top management has a responsibility to indicate the path the organization should take, including "the standards of knowledge to be created". Between these two levels are middle managers "who bridge the gap between the visionary ideas at the top and the sometimes chaotic reality of those in the front line of business". However, it is in the middle positions that the link between the other two resides so that "they are in a key position to transform reality according to the company's vision, often serving as synthesizers of the tacit knowledge of top management and first line employees, making it explicit and incorporating it into the production process".

Also, Takeushi \& Nonaka (2008), emphasize the importance of the various levels of management, especially when knowledge has to be recreated. It is at these times that top management has to protect creativity and innovation while maintaining a sense that there is a direction and it is worth continuing to focus on knowledge as the "engine" of the organization's development. The role of middle managers then becomes vital since, by their position, they are at the "intersection" of the vertical and horizontal information flow. That is, they are like a "bridge" between the top view and the operational reality of those who deal directly with the customer and the market, and ultimately mediate "what is and should be", so that existing reality mirrors the vision of the organization, and is able to convert tacit knowledge of top management and operations into explicit knowledge.

Knowledge management is a concept that is understood, quoting Serrano \& Fialho (2005, p.2), "as a broader and interdisciplinary view than the concept of "intellectual capital" and more operational than "the learning organization" essentially involves sharing individual knowledge for the formation of organizational knowledge" [16]. Also, according to these authors (2005) the KM seeks much more than theoretical explanations about the complex reality of organizations, as it not only tries to simplify the various organizational dimensions but also indicates how to create ways of acting in favour of creating structures more adapted and competitive, that is, in the view of Straus et al. (2012, p.55) "The role of Knowledge Management in organizations is to provide conditions to create, acquire, organize and process strategic information, and generate (including financial) benefits, increasing competitiveness".

Lopez (2014) summarizes the importance of using organizational KM to its function as a catalyst for organizational efficiency, by creating conditions for the perception of what the organization already knows, and what it still needs to know, in order to implement solutions that enable the long-sought competitive advantage that helps achieve the financial balance and social welfare of employees. It is in this context that the role of managers stands out, as stated by Strauhs et al. (2012, pp.56-57).

Management needs to establish the areas to which employees should direct their learning efforts (focus); set goals (strategy); and instituting cultural elements aimed at innovation, learning and commitment (motivation). To do so, there must be knowledge sharing from the highest positions for all sectors of the company.

In this context, $\mathrm{KM}$ is crucial for both human resources and organizations to remain competitive and in some cases even survive. Knowledge - as we have known it so far - is the property of employees from the moment they acquire it. However, organizations should pay special attention to knowing how to use and retain it, as stated by Oliveira (2013, p.8). "Remember that an organization's information is so valid that companies tend to generate bankruptcy with employees leaving or even evading strategic information" [11].

Thus, a relevant element in KM is the capacity for knowledge retention, so that capacity involves the implementation of mechanisms dedicated to this "combat", as Strauhs et al. (2012) "In order to avoid situations where organizational knowledge depends on the goodwill of managers and employees, the memory of the few, the availability of time and other resources, it is convenient to implement the process of documentation of lessons learned".

It is in this framework, that is, the ability to acquire, create, share and retain knowledge that KM, through its tools, is fundamental. As Batista points out about the study of KM practices in public entities, (2004, p.7) "Many institutions do not know or use the term "Knowledge Management", however, they perform processes - using techniques and tools which can be classified as knowledge management practices".

In order to have an idea of what kind of resources that institutions can use to implemented KM, Table 1 aggregates knowledge management tools released by: (Batista, 2004; Oliveira, 2013; UNDP, 2014; Straus et al., 2012): 
Table 1. Knowledge Management practices

\begin{tabular}{|c|c|}
\hline Practices & Objectives \\
\hline $\begin{array}{l}\text { Talent and Opportunity } \\
\text { Bank }\end{array}$ & Facilitates selection of human resources based on competency map \\
\hline $\begin{array}{l}\text { Supporting Technology } \\
\text { Tools }\end{array}$ & $\begin{array}{c}\text { Software and hardware, supporting knowledge management practices such } \\
\text { as data storage and availability, and decision making }\end{array}$ \\
\hline Knowledge Community & $\begin{array}{l}\text { Forum that allows the exchange of ideas / experiences, and aims to prevent } \\
\text { the loss of knowledge due to the departure of employees }\end{array}$ \\
\hline Communities of practice & $\begin{array}{l}\text { Computer tools for interaction between collaborators such as: Chat, forums } \\
\text { and messages designed for project and research and development issues }\end{array}$ \\
\hline $\begin{array}{l}\text { Organizational Knowledge } \\
\text { Mapping }\end{array}$ & $\begin{array}{l}\text { Avoid the problems of tacit knowledge - associated with "irreplaceable" } \\
\text { employees, as they allow the registration of knowledge resulting from the }\end{array}$ \\
\hline Knowledge repositories & creation of products, services, processes and customer relationships. \\
\hline Mentoring & $\begin{array}{l}\text { Knowledge transfer from a more experienced employee to another who } \\
\text { needs support to evolve or deal with new situations }\end{array}$ \\
\hline Learned lessons & $\begin{array}{l}\text { Databases, and campaigns to disseminate these lessons to "embody" the } \\
\text { learning vision before, during and after events }\end{array}$ \\
\hline Workshops and Seminars & Sharing experiences \\
\hline Organizational Memory & $\begin{array}{l}\text { Transform knowledge into the organization's heritage by capturing and } \\
\text { disseminating information }\end{array}$ \\
\hline Concept maps & Aim at optimizing problem understanding and finding solutions quickly \\
\hline How-To Guides & Facilitate insertion and intervention \\
\hline Best Practice Bank & $\begin{array}{l}\text { Repository of procedures, taken as correct, through experience, and available } \\
\text { to all sectors of the organization. }\end{array}$ \\
\hline "Exit" Interviews & Enable the capture of knowledge of those who want to leave the organization \\
\hline
\end{tabular}

Another important aspect for KM is the impact of his assessment, as quoted by UNDP (2014, p.71). "And without success in assessment, it is unlikely that it will be possible to identify what works and what that doesn't work, and therefore make an informed judgment about what to keep doing and what to change" [24].

Approaching now the area of Vocational Training (VT), it can be seen how organizations value knowledge by using vocational training to provide their employees with the necessary skills for knowhow, enabling them to maintain innovation and competitiveness. In this context, it is interesting to mention a study by Rodrigues (2014, p.97) done in the largest car manufacturer in Portugal, "In general, the institutional documents reflect the centrality given to training, both for the development of competences. as the reinforcement of the company's strategic values, becoming a fundamental pillar for its own growth" [13].

In this regard, it is also important to refer to the quote from Santos (2008, p.199) "Vocational training is widely recognized as a "sine qua non" condition for raising the productivity index of a Labor Organization" [15]. Consequently, it will be the country and society in general that will feel the result of a vocational training system based on solid knowledge bases, that is, according to Rodrigues (2016, p.20) "In this sense, the practices and policies of Vocational training can be seen as a methodical process of instruction whereby people improve their knowledge and skills, thereby increasing their technical or professional qualifications". VT is an instrument to improve knowledge and skills that, as a consequence, will bring benefits to individuals and organizations, or as stated by Rodrigues $(2016$, p.12) "Inherent in the performance of any organizational function is always a process of learning. (...) In the first contact with his/her job, the worker will have to mobilize knowledge, whether it is already achieved in the education system, or that it will still achieve at the same time as practical know-how".

For this cycle: learning, new knowledge, skills, know-how, and competitive advantage to be fulfilled, it is essential that the organizations, providing the knowledge and the technicians who have the responsibility to transmit it, have the necessary and appropriate conditions and knowledge to meet the needs of trainees and businesses. In this regard, the trainer, according to Santos (2008, p.13), "needs first of all to be trained in the knowledge inherent in the subjects he will instruct, in order to feel good (...) in order to achieve in the trainees group a feeling of continuous appreciation", and the organization, according to the same author (2008, p.28), being"the main axis in the effectiveness of Vocational Training. The pillar of this axis should be based on competent, mature and minimally experienced global Pedagogical Management. Around this axis will be well-trained trainers with technical and communication skills".

In this sense, organizations have responsibility for how they acquire, develop, and manage the knowledge of those who make knowledge their 
professional activity. This environment resembles the ba described by Takeushi \& Nonaka (2008), where the organizational environment is a key factor in the "growth" of employees and the entity. In another aspect, but equally important for organizations and training technicians, says Drucker (2012, p.201). "The organization has to earn loyalty by proving to its knowledge workers that it can offer them exceptional opportunities to put their knowledge in practice" [4].

As stated by Martins (2018), the knowledge base is the set of competencies that, in turn, are a set of capabilities and technology in which learning, both individual and organizational, gives rise to a specific competence that becomes essential when leads to added value, either by creating value, perceived by customers, or by reducing operating costs. In this context, for Strauhs et al. (2012) Human resources are vital in the learning process and innovative capacity of companies, but for this, skills are needed that can only be achieved by having a skills management structure that involves identifying gaps and implementing training, appropriate training and career management for each employee. It is in terms of competencies that, as they argue (Sobral, Chambel \& Castanheira, 2014; Rodrigues, 2016), one can contribute to raising motivation levels [17].

\section{Methodological Approach}

The methodology adopted to achieve the objectives of this research is the study of Multiple Cases, on the one hand, because it feels that is the most appropriate, according to Yin (2009), the method investigates contemporary and real life phenomena and allows data triangulation in order to make the study more robust. On the other hand, being an exploratory study with more than one entity, this methodological approach allows the comparison of results and inference of conclusions [27].

Thus, the general objective is to investigate how KM can be important in the success or improvement of vocational training processes as a product to be made available to the client. The investigation of these phenomena will also contribute to the identification of development level of KM, as well as the presentation of possible solutions that add value to this area of the entities analyzed. To help achieve this overall goal the following specific objectives have been met:

- Highlight KM procedures;

- Reveal the mechanisms of knowledge acquisition, transfer and retention;

- Identify the type of management influence;

- Unravel how KM is perceived;

- Understand the dynamics of knowledge development in training technicians;

- Understand how knowledge is transformed into added value;
- Understand the influence of KM on the success of vocational education practiced;

- Check the influence of clients (trainees) in the KM process.

The first five objectives are related to question No.1 and the last three are related to question No.2 explained below.

Branski, et al. (2010, p.2) state that "Whatever the purpose, research questions are the starting point and help the researcher to stay focused on his or her object" [3], so, after an exploratory phase and taking into account previous findings, it is important to raise the research questions which this study seeks to answer.

In this sequence, because it is intended to understand to what extent the main activity of organizations - Vocational Training - may be conditioned, in its success, by the way knowledge is managed, the questions are as follows:

1 - How is the knowledge Management process presented by Vocational Training institutions?

2 - What is the relevance of this process to the success of the training activity?

Beyond the objectives and the research questions, the propositions were developed, knowing that they have the mission to indicate what will have to be analyzed in the research work and, in some way, to help to search the evidences with interest for the research. In this respect it is worth remembering what advises Yin (2001, p.43) "Without such propositions, a researcher may be tempted to collect "everything" something absolutely impossible to do" [26], or as the same author points out in (2009, p.28) "each proposition directs attention to something that should be examined within the scope of the study. Only if you have to make some propositions will you go in the right direction".

In this sequence, the propositions are as follows:

1 - Institutions demonstrate a culture of KM;

2- $\mathrm{KM}$ is understood as an advantage (added value);

3 - Leadership is proactive in the KM process;

4 - Evaluation mechanisms exist and are seen as a means of continuous improvement;

5 - The organizational environment is conducive to the valorisation of "formative" knowledge;

6 - Training success is influenced by KM.

Regarding the unit of analysis, according to Yin (2009) he states that, in particular, individuals, small groups, organizations, or partnerships can be considered. Thus, it is assumed that the unit of analysis of this research is the organization and the respective process of $\mathrm{KM}$.

In this context, it is important to note that, in this case, the study assumes a role of verification of replication, Yin (2001, p.68), namely: "Here, an important perception that one must have is to consider multiple cases as one would consider 
multiple experiments - that is, to follow the logic of replication". This approach also takes into account the possibility that multiple case studies provide by helping to validate prepositions by crossing entity data, according to the advice of Yin $(2009$, p. 20) "The case study can cover multiple cases and then draw a single set of "cross case" conclusions".

As for the type of project, that is, holistic or incorporated, according to the characterization given by Yin (2001), this can be considered a multiple case holistic project because it comprises a single unit of analysis and more than one case, or as says Yin (2001, p.64) when distinguishing between embedded and holistic, "In contrast, if the case study examined only the global nature of a program or organization, a holistic project would be the denomination used."

Referring to the assessment adopted, it can be assumed that it is qualitative and quantitative because it is understood that, on the one hand, the qualitative one is best suited to the collection of evidence, as stated by Martins (2008, p.23) "assessment may be qualitative and, in this case, it will seek to describe, understand and explain discourse behaviours and situations"[8] and, on the other hand, the possibility of using quantitative analysis, namely through a questionnaire, which acts as a reinforcement of data collection.

Because it is expected that the practice in both entities, related to $\mathrm{KM}$ and its influence on the training process, is identical to the situations listed in the literature review, we can refer to Yin's (2009) statement pointing out that there is a literal replication. although they may have similar or contrasting results.

Yin (2009) adds that the use of these data sources will have benefits beyond their validity and reliability, being an important aspect, which results from the use of various sources, the triangulation of data in order to, as stated by Yin (2009, p.116) "Corroborate the same fact or phenomenon".

The data analysis method for the questionnaire is the Likert scale, which corresponds to five levels of agreement, or response disagreement, with the scale graduated from 1 to 5 , or positive because 1 corresponds to "Totally Disagree" and 5 corresponds to "Strongly Agree", thus offering the possibility of converting qualitative data for quantitative analysis. The analysis uses the average of the answers in each degree of agreement and the respective percentage, using the software Excel.

The interview is semi-structured, or semidirective, because, according to Quivy \& Campenhoudt (2005), it is composed of a series of guide questions - relatively open - through which the interviewer ensures not to deviate from the objectives of the interview [12].

Twelve statements are used in the questionnaire and in the interview the same number of questions.
The interview grid was structured in order to be able to confront the information gathered in the questions/prepositions created and contribute to the comparison of the interviewees' testimonies with the presented theoretical framework. Content analysis will be the method used, using the three-step method of Bardin (2016), pre-analysis, exploration and processing of data [1], obtained through NVivo software. (v.12).

In these circumstances, the analysis allowed to create eight thematic categories and thirteen subcategories as summarized in Table 2:

Table 2. Content Analysis Structure

\begin{tabular}{|c|c|}
\hline \multicolumn{2}{|c|}{ Content Analysis } \\
\hline Category & Subcategory \\
\hline $\begin{array}{l}\text { Knowledge } \\
\text { Management }\end{array}$ & $\begin{array}{l}\text { - Knowledge Management } \\
\text { Perception } \\
\text { - Knowledge management } \\
\text { characterization }\end{array}$ \\
\hline KM Procedures & Means and approaches \\
\hline $\begin{array}{c}\text { The } \\
\text { organizational } \\
\text { knowledge } \\
\end{array}$ & $\begin{array}{c}\text { Knowledge Acquisition, } \\
\text { Creation, Transfer, and } \\
\text { Retention } \\
\end{array}$ \\
\hline $\begin{array}{l}\text { Management } \\
\text { influence }\end{array}$ & $\begin{array}{c}\text { - Strategic Management } \\
\text { - Intermediate Management }\end{array}$ \\
\hline $\begin{array}{l}\text { Knowledge } \\
\text { dynamics in } \\
\text { training } \\
\text { technicians } \\
\end{array}$ & $\begin{array}{l}\text { - Organizational environment } \\
\text { - Involvement of vocational } \\
\text { training technicians }\end{array}$ \\
\hline $\begin{array}{l}\text { Knowledge is } \\
\text { an asset }\end{array}$ & $\begin{array}{c}\text { - Company Performance and } \\
\text { Knowledge Management } \\
\text { - Innovation and } \\
\text { competitiveness }\end{array}$ \\
\hline $\begin{array}{l}\text { Knowledge } \\
\text { management } \\
\text { and training } \\
\text { success }\end{array}$ & $\begin{array}{l}\text { - Knowledge management } \\
\text { and effectiveness of } \\
\text { vocational training } \\
\text { - Assessment of the influence } \\
\text { of KM on vocational training }\end{array}$ \\
\hline $\begin{array}{l}\text { Influence of } \\
\text { clients on } \\
\text { knowledge } \\
\text { management }\end{array}$ & Customer Opinion \\
\hline
\end{tabular}

In the Portuguese entity, all six senior management positions were involved, and a total of six training technicians were involved, corresponding to $70 \%$ of the technicians over one year old link to the entity. In the Spanish case, it was also possible to have the participation of senior managers equivalent to those of Portugal, as well as the number of training technicians, and in this category the collaboration, in relation to the total of training technicians in the automotive area, was around $60 \%$. Data collection took place in a timeframe between November 2018 and August 2019, and the analysis was performed until October 2019. 


\section{Findings}

Regarding document analysis: Activity Reports, Organizational Charts, Management Risk Prevention Plan, Training Assessment Reports, Educational Legislation, Teachers' Guides, and Entity Mobility Protocols were consulted.

The analysis made shows that, in the case of the Portuguese entity, there are many activities related to what the literature review understands as KM. Although there is no formal KM system with direct accountability and a structure in place for the acquisition, creation, dissemination and retention of knowledge, it is true that the reported activities can involve training technicians in the stages of creation, acquisition and dissemination. It is clear that, for this to happen, there must be the involvement of strategic and intermediate management.

It can be seen that there is an allusion to areas such as innovation and concern for the customer and the product available, and in practical terms, the existing evaluation procedures allow obtaining data for the quality of training practiced.

The Spanish organization is very similar to the Portuguese in terms of structure and initiatives related to knowledge, confirming the allusion to the need to improve the skills of employees in general, and training technicians in particular, and practices aimed to create knowledge acquisition and sharing, however, it is not possible to identify knowledge retention measures. Also, in this entity, it is obvious that there is no formal structure dedicated to KM. It is not possible to identify a process for assessing the impact of $\mathrm{KM}$ on the training provided and the technicians who develop it. Compared to the national entity, there is not such a big bet on disclosure of the entity and analysis of market needs.

Using basic descriptive statistics measures, a quantitative analysis was made of the data provided by the questionnaire, and (Table 3 ) reveals the results:

Table 3. Questionnaire Result

\begin{tabular}{|c|c|c|c|c|}
\hline \multirow{2}{*}{ Affirmation } & \multicolumn{2}{|c|}{ Portugal } & \multicolumn{2}{|c|}{ Spain } \\
\hline & $\%$ & Average & $\%$ & Average \\
\hline 1 - I know what Knowledge Management means & 86.7 & 4.08 & 91.7 & 4.08 \\
\hline $\begin{array}{l}2 \text { - There are Knowledge Management practices in the entity } \\
\text { where I work }\end{array}$ & 58.3 & 3.42 & 66.6 & 3.42 \\
\hline $\begin{array}{l}3 \text { - The management of this entity is involved in the } \\
\text { Knowledge Management process }\end{array}$ & 50 & 3.33 & 33.3 & 3.00 \\
\hline $\begin{array}{l}4 \text { - The implementation of Knowledge Management practices } \\
\text { contributes to the improvement of business performance }\end{array}$ & 100 & 4.67 & 91.6 & 4.25 \\
\hline $\begin{array}{l}5 \text { - Knowledge Management contributes to the effectiveness of } \\
\text { the training developed }\end{array}$ & 100 & 4.58 & 83.4 & 4.25 \\
\hline $\begin{array}{l}\text { 6- The current organizational culture generates skills in } \\
\text { training technicians }\end{array}$ & 75 & 3.75 & 83.3 & 3.83 \\
\hline $\begin{array}{l}7 \text { - Is there a culture of tacit (personal) to explicit (shared or } \\
\text { public) knowledge transformation }\end{array}$ & 25 & 3.08 & 50.0 & 3.50 \\
\hline 8 - Training technicians engage in knowledge creation & 91.6 & 4.00 & 58.4 & 3.67 \\
\hline $\begin{array}{l}9 \text { - The product developed (knowledge) takes into account } \\
\text { market needs }\end{array}$ & 83.3 & 3.83 & 66.7 & 3.83 \\
\hline $\begin{array}{l}\mathbf{1 0} \text { - The entity I work for innovates and gains competitive } \\
\text { advantage }\end{array}$ & 83.4 & 3.92 & 50.0 & 3.50 \\
\hline $\begin{array}{l}\mathbf{1 1} \text { - There are mechanisms for verifying the impact of } \\
\text { Knowledge Management on vocational training }\end{array}$ & 0 & 2.67 & 8.30 & 2.42 \\
\hline 12 - The process of clients vocational training is evaluated & 41.7 & 3.50 & 50.0 & 3.25 \\
\hline
\end{tabular}

The percentage shown is the sum of the Agree and Strongly Agree values, as both choices are in the same direction.

The data show that the highest values are in statements 4 and 5 , both in percentage and on average. These statements refer to the advantages of using KM, both for the company's performance and for the effectiveness of the training developed. On the opposite side is the ability to verify the impact of $\mathrm{KM}$ on vocational training with an average of 2.67 , and this is due to the difficulty in implementing measurement systems resulting from intangible activity. The value of the shift from tacit to explicit knowledge is also low, especially in percentage (25\%), although the average is slightly above the minimum threshold: 3.08 on a scale of 1 to 5 . All other values are above average and with satisfactory percentages, with only the evaluation of the formative process slightly below $41.7 \%$.

Regarding the Spanish entity, it is clear that the highest values are those of statements 4 and 5, as in Portugal, and the lowest is that of statement 11, identical to Portugal, with 2.42 on average, tacit-toexplicit knowledge transformation is slightly higher 
in Spain with 3.50, compared to 3.08 in Portugal. One of the values that has had little positive results is the involvement of management in the dynamization of the knowledge management process with an average of 3.00, which, although slightly lower than in Portugal, is not too far away, as the difference is 0.33 in average. The recognition that there are KM practices is positive and identical in both entities, with an average of 3.42. A key aspect was the highlevel answer given to statement No.1, which has to do with knowledge about the meaning of KM, which stands at 4.08 on average.
This indicator shows that the vast majority of respondents have an idea of what the study involves and this is crucial for the interview phase.

The analysis of the interviews allowed us to infer that the opinions are in line with the questionnaire in both entities, so that the answers to the questions are also similar in both organizations. Table 4 identifies the correspondence between the questionnaire statements and the interview questions, that is, what was considered in the interview answers to infer and corroborate.

Table 4. Questionnaire and Interviews correspondence

\begin{tabular}{|c|c|}
\hline Questionnaire & Interview \\
\hline 1 - I know what Knowledge Management means & 1 -What do you mean by Knowledge Management? \\
\hline \multirow{3}{*}{$\begin{array}{l}2 \text { - There are Knowledge Management practices } \\
\text { in the entity where I work }\end{array}$} & $\begin{array}{l}2 \text { - How do you characterize it, in everyday life, of this } \\
\text { entity? }\end{array}$ \\
\hline & $\begin{array}{l}3 \text { - What means / tools are used for its } \\
\text { implementation? }\end{array}$ \\
\hline & $\begin{array}{l}4 \text { - How knowledge is acquired, created, shared and } \\
\text { retained? }\end{array}$ \\
\hline $\begin{array}{l}3 \text { - The management of this entity is involved in } \\
\text { the Knowledge Management process }\end{array}$ & $\begin{array}{l}5 \text { - What is the involvement of strategic and } \\
\text { intermediate management in the knowledge } \\
\text { management process? }\end{array}$ \\
\hline $\begin{array}{l}4 \text { - The implementation of Knowledge } \\
\text { Management practices contributes to the } \\
\text { improvement of business performance }\end{array}$ & $\begin{array}{l}6 \text { - What are the benefits to the company's } \\
\text { performance that Knowledge Management provides? }\end{array}$ \\
\hline $\begin{array}{l}5 \text { - Knowledge Management contributes to the } \\
\text { effectiveness of the training developed }\end{array}$ & $\begin{array}{l}7 \text { - How Knowledge Management options affect } \\
\text { Vocational Training effectiveness? }\end{array}$ \\
\hline $\begin{array}{l}6 \text { - The current organizational culture generates } \\
\text { skills in training technicians }\end{array}$ & $\begin{array}{l}8 \text { - Is the organizational environment conducive to the } \\
\text { development of knowledge and competencies / skills in } \\
\text { training technicians? In what way? }\end{array}$ \\
\hline $\begin{array}{l}7 \text { - Is there a culture of tacit (personal) to explicit } \\
\text { (shared or public) knowledge transformation }\end{array}$ & \multirow{2}{*}{$\begin{array}{l}9 \text { - How does individual knowledge influence the } \\
\text { organization, and that of the organization influences } \\
\text { the individual, namely in terms of the training } \\
\text { provided? }\end{array}$} \\
\hline $\begin{array}{l}8 \text { - Training technicians engage in knowledge } \\
\text { creation }\end{array}$ & \\
\hline $\begin{array}{l}9 \text { - The product developed (knowledge) takes } \\
\text { into account market needs }\end{array}$ & \multirow{2}{*}{$\begin{array}{l}10 \text { - How do clients' training needs are reflected on the } \\
\text { training provided? }\end{array}$} \\
\hline $\begin{array}{l}12 \text { - The process of clients vocational training is } \\
\text { evaluated }\end{array}$ & \\
\hline $\begin{array}{l}10 \text { - The entity I work for innovates and gains } \\
\text { competitive advantage }\end{array}$ & $\begin{array}{l}11 \text { - Which innovations - in the "training" product - } \\
\text { contributed to the entity's competitive advantage? }\end{array}$ \\
\hline $\begin{array}{l}11 \text { - There are mechanisms for verifying the } \\
\text { impact of Knowledge Management on vocational } \\
\text { training }\end{array}$ & $\begin{array}{l}12 \text { - What measures are in place to assess and measure } \\
\text { the influence of Knowledge Management on clients' } \\
\text { vocational training? }\end{array}$ \\
\hline
\end{tabular}

Regarding question No.1, answers were obtained as follows: (I6 - Portugal) "(...) These are a set of processes and systems that allow the systematization of an organization's intellectual capital in order to make it a learner and capitalize on its ability to the aforementioned affirmation objective in the market" and (I1- Spain), "I understand that it is the set of strategies by which everything one knows and knows can be transmitted to the community". In the case of question No.2 we have opinions such as: "I characterize it as being necessary to offer qualified education, and according 
to the new trends in the working world" (I2 - Spain), or, in the Portuguese case (I12), "I have a positive opinion (...)". However, according to the opinion of some elements, there is the perception that there is not yet a formal structure that allows the dissemination of knowledge.(I1-Portugal) "Existing informally, it is not systematized and appropriate by stakeholders, who think that knowledge is individual and not corporate." For question No.3, comments have appeared in the Portuguese entity that reveal the general feeling of using some means, as referred to by (I1), among others, which are:"Training of trainers", "IT resources", cooperation and sharing of exercises and technical information, as mentioned by (I3) "Then the company has implemented knowledge sharing processes, namely exercise sharing, new courses, internal training, databases, meetings, where there is some sharing, among other ways / means". In the Spanish entity the following means were mentioned: (I2) "Audiovisual media and technical documentation", or (I9) “(...) technical days, weekly training sessions where participants share their knowledge and classroom activities, and virtual classes".

Concerning the acquisition, creation, transfer and retention of knowledge, the following comments were obtained: (I7-Spain) "The conclusions of all these courses and working groups are published so that all interested training technicians have free access", or, in the Portuguese case, that of (I4) "The retention of knowledge is in the documents prepared and stored in the organization, through computer records".

In question 5, respondents referred to the influence of management, strategic and intermediate, as: (I3Portugal)"Strategic management creates working, or operational, methods that foster knowledge retention and sharing". Although opinion in Spain is somewhat less favourable, responses were also reported that denounce management involvement, for example: (I9) regarding strategic management "The governing body acts as the coordinator and driver of all management activities".

The sixth question, linked to the benefits that knowledge management can bring to the performance of the entities, has a very positive consensus, given by answers such as (I1 - Portugal), "Comparative gains with other entities that start the process, and internal gains by not repeating processes, procedures or errors, with substantial time savings in preparation and implementation "and, in the Spanish case, for example (I3) mentions that" Generate guide documents and help the entire educational community, whether to improve the functioning of the training centre or to improve technical education".

For question No. 7, expressions of interviewees emerged giving great relevance to knowledge management in the success of vocational training.
On the Spanish side (I2) states: "Always be aware of the news of each sector, as it is difficult to keep up to date", and (I6) "Everyone is benefited, but the most benefited is the student". The Portuguese interviewees, in the same register, state: "In any vocational training company, knowledge management takes on an even more important role, since these types of companies are true "knowledge warehouses" (I2).

In question No. 8 the reactions indicate an environment of some facilitation in the development of knowledge of the training technicians, the example of Portugal comes from the expression of (I8) "Yes, (...) we have the opportunity to practice before teaching the subjects", and that of Spain by (I5) "Yes, with the exchange of information and knowledge", and by (I11) "(...) the training and resource centre effectively enables the creation of content".

The question that addresses tacit and explicit knowledge, no. 9, is commented with expressions such as: (I2) "Any increase in knowledge, from the individual to the company or vice versa, if properly used, will result in an improvement of the training provided", (I7) "Both knowledge complement each other (...)", this in the Portuguese entity. In Spain the (I1) refers "Individual knowledge and more experience decisively influence the good management of knowledge. The human qualities of the person are also very important (...). All material can always be put on the net for the benefit of all".

The customer needs are addressed by the question no. 10 , and in the Portuguese entity there is concern, (I1) "According to the customer's needs the contents are conceived", or the (I8) "The formative needs of the customers have obliged the organization developing new courses and updating existing ones". In the Spanish entity, these opinions are highlighted (I11) "By questioning the departments about training needs, activities are called to cover these demands", or the (I9) "By annual questionnaires to the departments of all centres".

Concerning innovations - question 11 - in order to increase competitiveness, the following answers from Portugal should be highlighted: (I2) “(...) the continuous improvement of installations and equipment, the alteration/ simplification of processes or the updating of tools computer systems that have been made available"; (I6) "(...) the organization is responding well to customer needs, particularly with regard to emerging training such as hybrid and electric vehicles (...)". And from Spain: "Using more computer tools in education" (I5); From (I2) comes the idea of social networks: "How can we suppose needs are detected by analyzing social networks and filtering their information", and (I11) mentions the collaboration with other entities "European programs and mobility between teachers from other countries". 
The last issue, which addresses the issue of KM assessment, is the least agreement deserving on the part of the study participants in both organizations, so the opinions are: In Portugal, (I1) "No there are measures in place to evaluate and measure the influence of Knowledge Management on the vocational training of clients", (I3) "I do not know if what is implemented makes this assessment". In Spain, (I2) "Student evaluation only", (I9) "Final evaluation of each activity, to analyze the degree of satisfaction, acquired knowledge and proposals for improvement".

The objective of corroborating the questionnaire choices through the interview answers was achieved in both organizations, because, in general terms, the interview answers are congruent with those of the questionnaire.

Analyzing now the results of the information with a view to inferences regarding the objectives set, it can be seen that all of them were achieved, both related to question No. 1 and those related to question No. 2 .

In propositions case, the results of the data collected ensure confirmation, in agreement, except that concerning the aspect of the evaluation, being addressed only the evaluation of the training processes and not the impact of the KM processes. In the case of the third proposition "Leadership is proactive in the KM process", research shows that there is some involvement of top and middle management. However, this organizational element may become more proactive in the area of $\mathrm{KM}$ if it strengthens this aspect, which increasingly promotes more competitive and robust organizations. One point in which we felt little bet is on retention and even "keeping" the knowledge that organizations are acquiring and creating.

\section{Conclusions}

Reached the conclusions, it is important to understand if the questions were answered and to what extent. Thus, the first question: How is the knowledge management process that vocational training institutions present?

It can be said that this question was fully answered. That is, the crossing of the information by the data triangulation technique allowed to obtain information, with confidence, regarding the characterization of the way knowledge is managed, even coming to the conclusion that a formal structure with responsible, clear objectives is not implemented and measurement indicators in both institutions are not present.

The second question aimed to explore: What is the relevance of this process to the success of the training activity?

This question is answered practically in its entirety. This is because, the information obtained disclosed how knowledge can be decisive in the affirmation of the product and, consequently, of organizations in the vocational training market, indicating that $\mathrm{KM}$ is understood as an asset for vocational training. The influence of $\mathrm{KM}$ on the success of the professional training practiced was indicated as positive and fundamental, making it possible to affirm that the professional training depending, essentially, on the knowledge, will be better the better the knowledge is managed. In order for this management to be successful, it must also be accompanied by an evaluation mechanism that points the way to achieving the best results.

In this context, it is verified that the results, at all levels, are very similar in both organizations, and are able to state that the characterization of knowledge management is acceptable, and the recognition of the influence of this management on the success of the formative activity is undeniable. However, it can also be inferred that the adoption of a system dedicated to knowledge management, as developed throughout the literature review, would be a way of enhancing the work already being done and bringing these two organizations to levels of structural development most interesting.

Finally, as mentioned above, this paper aimed to explore knowledge management in two vocational training institutions in the area of auto repair, having chosen to involve a Spanish entity for the implementation of the multiple case study aspect. The logic of the replication of results in order to consolidate or refute the propositions presented, was followed, and believed to have the same results because they are organizations with the same type of product and identical structures, which was verified, that is, it was found the replication of results.

The results allow us to understand a need to make KM the primary optimization tool for the most important resource of an organization that lives on knowledge, knowledge itself, whether private or public. This means that while organizations have some principles, activities, and methods that enable them to enhance the expertise of their technicians, they can still implement strategic measures that would improve performance that would, at the same time, bring benefits to both internal and external customers.

\section{References}

[1] Bardin, L. (2016). Content analysis. São Paulo: Edições 70.

[2] Batista, F. F. (2004).Learning Government: Knowledge Management in Federal Executive Organizations. Text for discussion no. 1022. Retrieved from:http://www.ipea.gov.br/portal/index.php ?option=com_content $\&$ view $=$ article $\&$ id $=4602 \&$ catid=310. Accessed at: 12.12 .2018

[3] Branski, R.M., Franco, R.A.C., \& Lima Jr., O.F. (2010).Case study methodology applied to logistics. XXIV ANPT. Retrieved from: 
http://www.lalt.fec.unicamp.br/scriba/files/es crita\%20portugues/ANPET\%20\%20METODOL OGIA\%20DE\%20ESTUDO\%20DE\%20CASO\%2 0\%20COM\%20AUTORIA\%20-\%20VF\%202310.pdf.

Accessed at: 05.05.2019

[4] Drucker, P.F. (2012). A functional society. Alfragide: Publications Don Quixote.

[5] Lopes, I. T. (2013). Management of intellectual capital and intangibles in the age of knowledge. Lisbon:Escolar Editora.

[6] Lopez, Y. (2014). Management information systems. Lisbon: Editora escolar.

[7] Magalhães, R. (2005). Fundamentals of organizational knowledge management. Lisbon: Editions Sílabo.

[8] Martins, G.A. (2008). Case Study: A Reflection on Applicability in Research in Brazil. Journal of Accounting and Organizations, 2 (2), 8-18. Retrieved from:http://www.redalyc.org/articleuloa?id=2 35217215002. Accessed at: 18.02.2019

[9] Martins, J.M. (2018). Knowledge Management Creation and transfer of knowledge. (2nd ed.). Lisbon: Editions Sílabo.

[10] Nonaka, I. (2007). The Knowledge-Creating Company. Harvard Business School, 162-171. Retrieved from:https://hbr.org/2007/07/theknowledge-creating-company.

Accessed at: 01.12.2018

[11] Oliveira, A.P. (2013). Knowledge Management: Study of knowledge management procedures in a Public University (Final Thesis, Federal Technological University of Paraná). Retrieved from:

http://repositorio.roca.utfpr.edu.br/jspui/bitst ream/1/919/1/PB_EGCF_VIII_2013_03.pdf. Accessed at: 21.12 .2018

[12] Quivy, R., \& Campenhoudt, Luc V. (2005). Research Manual on Social Sciences. (4th ed.). Lisbon: Gradiva.

[13] Rodrigues, S. P. (2014). Training and work: the case of Autoeuropa. In A.S. Caetano (Ed.), Organizational Training and Development Approaches and Case Studies in Portugal (pp.87 - 102). Lisbon: Mundos Sociais.

[14] Rodrigues, M. D. (2016). Skills development and updating: Training as a strategic human resources management tool - Case Study. (Master's Dissertation, Coimbra School of Education). Retrieved from:

https://com.rcaap.pt/bitstream/10400.26/176 99/1/Disserta\%C3\%A7\%C3\%A3o\%20\%20Ma gda\%20Rodrigues.pdf. Accessed at: 03.01.2019

[15] Santos, J.M. (2008). The modern trainer and the training organization: Techniques at the service of effectiveness and efficiency in vocational training. Coimbra: Almedina.
[16] Serrano, A., \& Fialho C. (2005). Knowledge Management: The new paradigm of organizations. (2nd ed.). FCA - Editores de Informática, Lda.

[17] Sobral, F., Chambel, M.J., and Castanheira, F. (2014). Employability training: Relationship with the emotional commitment and well-being of temporary and permanent workers. In A.S. Caetano (Ed.), Organizational Training and Development - Approaches and Case Studies in Portugal (pp.13 - 26). Lisbon: Mundos Sociais.

[18] Strauhs, F.R., Pietrovski, E.F., Santos, G.D., Oak, H.G., Pepper, R.B., \& Hairstyle, R.S. (2012). Knowledge management in organizations. Retrieved from: http://riut.utfpr.edu.br/jspui/bitstream/1/206 4/1/gestaoconhecimentoorganizacoes.pdf. Accessed at: 19.02.2019

[19] Stewart, Thomas A. (1999). Intellectual Capital: the new wealth of organizations. Lisbon: Editions Sílabo.

[20] Sveiby, K.E. (1998). The New Wealth of Organizations: Managing and Evaluating Knowledge Heritage. Rio de Janeiro: Campus.

[21] Takeushi, H., \& Nonaka, I. (2008). Knowledge management. Porto Alegre: Bookman.

[22] United Nations. (2005). Understanding knowledge societies in twenty questions and answers with the index of knowledge societies. Economic and Social Affairs. Retrieved from: https://publicadministration.un.org/publicatio ns/content/PDFs/ELibrary\%20Archives/2005 \%20Understanding\%20Knowledge\%20Societie s.pdf, Accessed at: 11.03.2019

[23] United Nations Development Programme. (2007). Knowledge management toolkit for the crisis prevention and recovery practice area. Retrieved

from:https://reliefweb.int/sites/reliefweb.int/f iles/resources/p\%26i\%20to\%20post.pdf

Accessed at: 24.03.2019

[24] United Nations Development Programme. (2014). UNDP Knowledge Management Strategy Framework 2014-2017. Retrieved from: https://www.undp.org/content/undp/en/hom e/librarypage/capacity-

building/knowledge/undp_s-knowledgemanagement-strategy.html

Accessed at: 27.12.2018

[25] Wan, J., Zeng, M., \& Zhu, Yahui. (2013). Case Study on Tacit Knowledge Management Systems Within X Company. Technology and Investment, 4 (2), 92100.Retrievedfrom:http://dx.doi.org/10.423 6/ti.2013.42011. Accessed at: 12.04.2019

[26] Yin, R. K. (2001). Case Study - Planning and Methods. (2nd ed). Porto Alegre: Bookman.

[27] Yin, R.K. (2009). Case study research - Design and methods. (4th ed). California: Sage. 